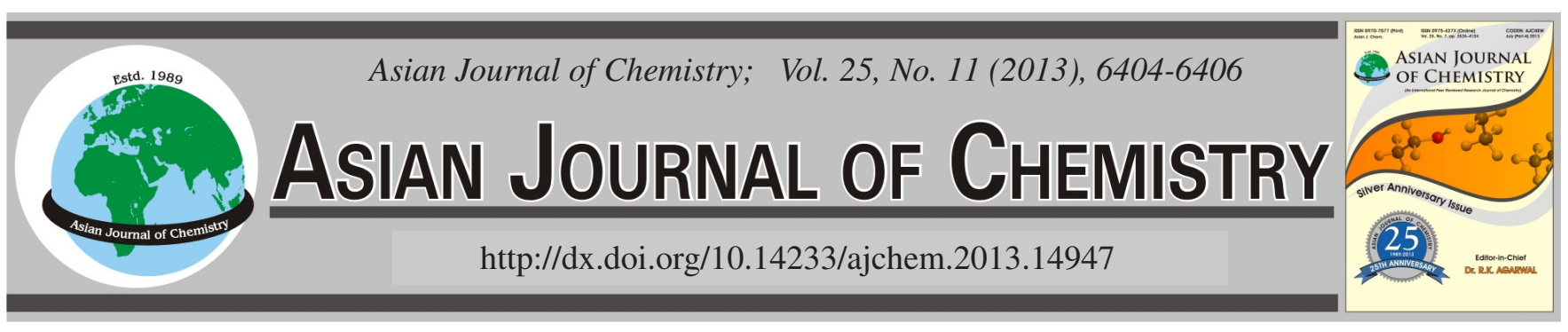

\title{
An Efficient Approach for the Deprotection of Esters Using Ionic Liquid as Nucleophile
}

\author{
Benmei Wei*, Zhiyong Zhang, ZhiQun Dai and Jintao Guan
}

School of Chemical and Environmental Engineering, Wuhan Polytechnic University, Wuhan, P.R. China

*Corresponding author: Tel: +86 27 83943956; E-mail: amei_xiaohua@163.com

An efficient approach for the deprotection of esters has been developed using ionic liquid as nucleophile in the presence of protic acid. Using methyl benzoate as a model compound, the best result was obtained by the combination of 1-methylimidazolium bromide and methane sulfonic acid with a conversion of $96 \%$ after $2 \mathrm{~h}$ at $120^{\circ} \mathrm{C}$.

Key Words: Deprotection, Ionic liquid, Carboxylic acids, Nucleophile.

\section{INTRODUCTION}

Esters are the most useful protective groups in synthetic organic chemistry ${ }^{1-2}$. Typically, deprotection of esters to carboxylic acids is performed by saponification with sodium or potassium hydroxides in water, lower alcohols or their mixtures $^{3}$. Besides saponification, esters can be hydrolyzed with various protic or Lewis acids ${ }^{4}$. However, both saponification and hydrolysis can be limited in the case of acid- or base-sensitive substrates. On the other hand, the use of Lewis acids such as $\mathrm{MgI}_{2}, \mathrm{AlCl}_{3}, \mathrm{AlBr}_{3}$ and $\mathrm{ZnBr}_{2}$ have a merit of mild reaction conditions but need to long reaction time and low conversion of ethyl protecting group ${ }^{5,6}$.

The properties of ionic liquids such as low vapour pressure, nonflammablility, recyclability and excellent chemical and thermal stability have made them environmentally attractive alternative to conventional organic solvents ${ }^{7,8}$. Ionic liquids have been successfully used in catalysis ${ }^{9,10}$, extraction $^{11,12}$, polymer science ${ }^{13,14}$, electrochemical ${ }^{15,16}$ and separation $^{17,18}$. In the past decade, ionic liquids have been reported for the deprotection reaction of ethers ${ }^{19,20}$ and aldehydes ${ }^{21,22}$. However, there are few reports on the deprotection of esters using ionic liquids. In our recently report, we have successfully developed the deprotection procedure of esters using chloroaluminate ionic liquid as catalyst and medium ${ }^{23}$.

Herein, we report the application of ionic liquids (1-4, Fig. 1) for the deprotection of esters to obtain the corresponding carboxylic acids in the presence of a proton source.

\section{EXPERIMENTAL}

All the chemicals were of regent grade and used as received. Melting points were taken on a micro melting point apparatus (model X-4, Tech Instruments, Beijing, China). ${ }^{1} \mathrm{H}$
NMR spectra were recorded on a Bruker AVANCE $400 \mathrm{MHz}$ spectrometer using $\mathrm{CDCl}_{3}$ as solvent and TMS as an internal standard (Bruker Corporation, Switzerland). IR spectra were recorded on a Nicolet AVATAR FT-IR 330 instrument (Thermo Electron Corporation, USA). The ionic liquids (1-4) were prepared by the literature methods ${ }^{24-26}$.

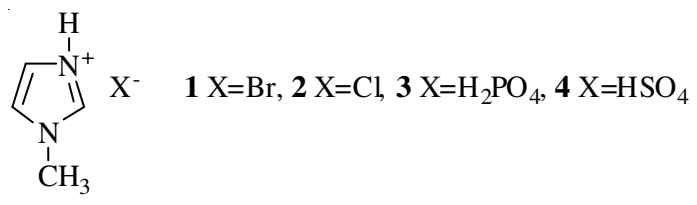

Fig. 1. Ionic liquids 1-4

Ester $(0.05 \mathrm{~mol})$, ionic liquid $(0.15 \mathrm{~mol})$ and protic acid $(0.15 \mathrm{~mol})$ were placed in a three-neck round bottom flask fitted with a stirrer, a thermometer, a reflux condenser and a drying tube at the top. The contents of flask were magnetically stirred and the oil bath temperature was maintained at $120^{\circ} \mathrm{C}$. The reaction was monitored by TLC. After the completion of reaction, the mixture was cooled to room temperature and extracted with anhydrous $\mathrm{Et}_{2} \mathrm{O}(3 \times 20 \mathrm{~mL})$. The combined ether phase was separated and dried with $\mathrm{Na}_{2} \mathrm{SO}_{4}$. Evapouration of the solvent afforded the crude product, which was purified by chromatography over a silica gel column (5\% EtOAc-hexane). All the products were characterized by IR, ${ }^{1} \mathrm{H}$ NMR and the spectral data were identical with those of authentic samples. Their melting points were in agreement with reference values ${ }^{27}$.

\section{RESULTS AND DISCUSSION}

To optimize the reaction conditions, we carried out the deprotection of methyl benzoate in ionic liquid 1-4 in the 
presence of various protic acids (Table-1). The reaction using the combination of methane sulfonic acid $(\mathrm{MsOH})$ and ionic liquid $\mathbf{1}$ on a $\mathbf{3}$ equivalence scales respectively was complete

\begin{tabular}{|c|c|c|c|c|c|}
\hline \multicolumn{6}{|c|}{$\begin{array}{c}\text { TABLE-1 } \\
\text { DEALKYLATION OF METHYL BENZOATE USING IONIC } \\
\text { LIQUIDS 1-4 AS NUCLEOPHILE }\end{array}$} \\
\hline Entry & $\begin{array}{l}\text { Ionic liquid } \\
\text { (equiv) }\end{array}$ & $\begin{array}{l}\text { Protic acid } \\
\text { (equiv) }\end{array}$ & $\begin{array}{l}\text { Temp. } \\
\left({ }^{\circ} \mathrm{C}\right)\end{array}$ & $\begin{array}{l}\text { Time } \\
\text { (h) }\end{array}$ & $\begin{array}{l}\text { Yield } \\
(\%)\end{array}$ \\
\hline 1 & $1(3)$ & $\mathrm{MsOH}(3)$ & 120 & 2 & 96 \\
\hline 2 & $2(3)$ & $\mathrm{MsOH}(3)$ & 120 & 2 & 92 \\
\hline 3 & $3(3)$ & $\mathrm{MsOH}$ (3) & 120 & 2 & 47 \\
\hline 4 & $4(3)$ & MsOH (3) & 120 & 2 & 34 \\
\hline 5 & $1(3)$ & $\mathrm{CF}_{3} \mathrm{COOH}(3)$ & 120 & 2 & 77 \\
\hline 6 & $1(3)$ & $\mathrm{HCOOH}(3)$ & 120 & 2 & 50 \\
\hline 7 & $1(3)$ & $\mathrm{CH}_{3} \mathrm{COOH}(3)$ & 120 & 2 & 25 \\
\hline 8 & & $\mathrm{MsOH}(3)$ & 120 & 2 & 28 \\
\hline 9 & $1(3)$ & & 120 & 10 & 0 \\
\hline 10 & $1(1)$ & $\mathrm{MsOH}(1)$ & 120 & 2 & 40 \\
\hline 11 & $1(2)$ & $\mathrm{MsOH}(2)$ & 120 & 2 & 77 \\
\hline 12 & $1(4)$ & $\mathrm{MsOH}(4)$ & 120 & 2 & 97 \\
\hline 13 & $1(1)$ & $\mathrm{MsOH}(1)$ & 120 & 12 & 95 \\
\hline 14 & $1(2)$ & $\mathrm{MsOH}(2)$ & 120 & 8 & 95 \\
\hline 15 & $1(3)$ & $\mathrm{MsOH}(3)$ & 80 & 2 & 65 \\
\hline 16 & $1(3)$ & $\mathrm{MsOH}(3)$ & 140 & 2 & 97 \\
\hline 17 & $1(3)$ & $\mathrm{MsOH}(3)$ & 120 & 1 & 72 \\
\hline 18 & $1(3)$ & $\mathrm{MsOH}(3)$ & 120 & 3 & 96 \\
\hline
\end{tabular}

${ }^{a}$ Reaction conditions: ester $(0.05 \mathrm{~mol})$, nonaqueous after $2 \mathrm{~h}$ in $96 \%$ yield (Table-1, Entry 1 ). As expected, similar result was obtained using the combination of ionic liquids 2 along with methane sulfonic acid, giving benzoic acid in $92 \%$ yield (Table-1, Entry 2). However, under the same conditions, the yields of benzoic acid are low using ionic liquids $\mathbf{3}$ and $\mathbf{4}$ (Table-1, Entries 3 and 4). The role of ionic liquids was to provide the necessary nucleophile, i.e. $\mathrm{Br}^{-}, \mathrm{Cl}^{-}, \mathrm{H}_{2} \mathrm{PO}_{4}^{-}, \mathrm{HSO}_{4}^{-}$, to attack the methyl group of methyl benzoate. Their activity order was consistent with their nucleophilicity order: $\mathrm{Br}^{-}>$ $\mathrm{Cl}^{-}>\mathrm{H}_{2} \mathrm{PO}_{4^{-}}>\mathrm{HSO}_{4^{-}}{ }^{28}$. Moreover, we also investigated the deprotection of methyl benzoate in ionic liquid $\mathbf{1}$ in the presence of other protic acids, $\mathrm{CF}_{3} \mathrm{COOH}, \mathrm{HCOOH}$ and $\mathrm{CH}_{3} \mathrm{COOH}$ (Table-1, Entries 5-7). The role of protic acids was to activate the carbonyl oxygen to make the methyl carbon susceptible to nucleophilic attack the resulting conjugate base. The activity order of protic acids is $\mathrm{MsOH}>\mathrm{CF}_{3} \mathrm{COOH}>\mathrm{HCOOH}>$ $\mathrm{CH}_{3} \mathrm{COOH}$. This result was consistent with the acidity of the protic acids. Use of protic acid methane sulfonic acid alone resulted in poor conversion of $28 \%$ (Table-1, Entry 8). Methane sulfonic acid is an extremely weak nucleophile. Furthermore, it is found that ionic liquid $\mathbf{1}$ alone is not sufficiently effective for the deprotection of methyl benzoate, with no detectable transformation being noted, despite heating for $10 \mathrm{~h}$ (Table-1, Entry 9). The reason for this result is that ionic liquid $\mathbf{1}$ is nonacidic, there is no acidic proton present. From these results, it is evident that both an efficient nucleophile and an effective proton source are required to achieve a smooth transformation of ester to carboxylic acid.

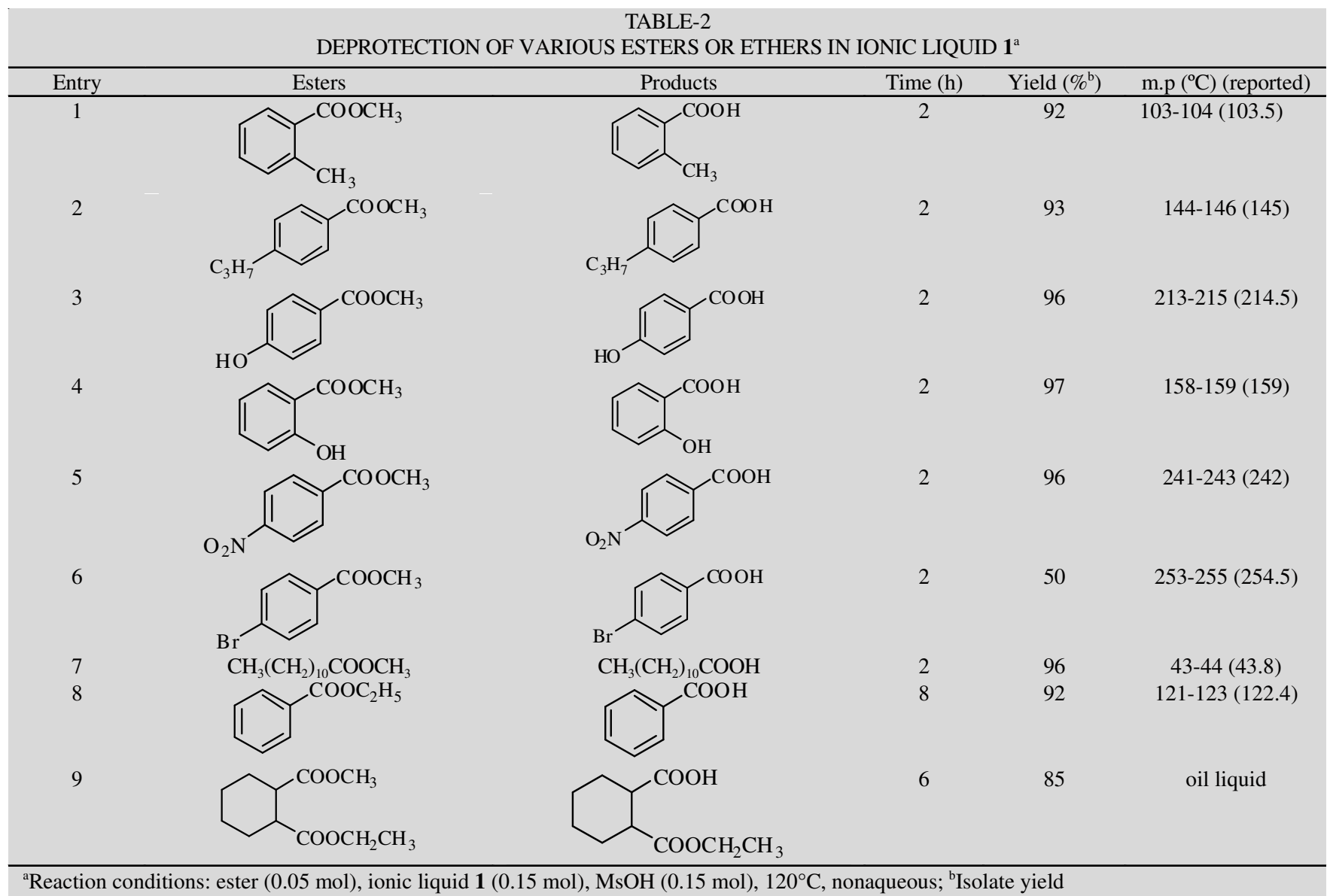

${ }^{\mathrm{a}}$ Reaction conditions: ester $(0.05 \mathrm{~mol})$, ionic liquid $1(0.15 \mathrm{~mol}), \mathrm{MsOH}(0.15 \mathrm{~mol}), 120^{\circ} \mathrm{C}$, nonaqueous; ${ }^{\mathrm{b}} \mathrm{Isolate}$ yield 
The effects of the ratio of ionic liquid and protic acid to ester on this transformation were also explored. In the $2 \mathrm{~h}$ reaction, conversion increased from 40 to $96 \%$ when the ratio was increased from 1 to 3 (Table-1, Entries 1, 10 and 11). Increase of the ratio to 4 has no significant effect on the conversion of benzoic acid (Table-1, Entry 12). However, prolonging the reaction time was found to significantly increase the conversion of methyl benzoate (Table-1, Entries 13 and 14).

We also investigated the effects of different reaction temperature and time on this conversion. The yield increased from 65 to $96 \%$ for a $2 \mathrm{~h}$ reaction period when the reaction temperature increased from 80 to $120^{\circ} \mathrm{C}$ (Table-1, Entries 1 and 15). Increase of the reaction temperature to $140{ }^{\circ} \mathrm{C}$ has a marginal effect on the yield of benzoic acid (Table-1, Entry 16). The yield increased from 72 to $96 \%$ with prolonging the reaction time from 1 to $2 \mathrm{~h}$ (Table-1, Entries 1 and 17) and extending the reaction time to $3 \mathrm{~h}$ has no practically effect on the yield indicating that the reaction is complete in $2 \mathrm{~h}$ (Table1, Entry 18).

To enlarge the scope of the deprotection method, deprotection of various esters has been performed using ionic liquid 1 in the presence of methane sulfonic acid, the results are shown in Table-2. Interestingly, this deprotection method is compatible with many functional groups. Clearly, the presence of alkyl, hydroxyl, nitro and bromine functions does not disturb ester cleavage (Table-2, Entries 1-6). Furthermore, the same conditions are effective for the deprotection of aliphatic esters (Table-2, Entry 7).

In case of such higher esters as ethyl benzoate, the conversion needs longer reaction time because of the steric hindrance of alkyl moieties. (Table-2, Entry 8). In the case of the compound, which possesses two different esters in the molecule, the selective deprotection was achieved under the conditions (Table-2, Entry 9).

\section{Conclusion}

In conclusion, we have developed a new and efficient approach for deprotection of esters using ionic liquid as nucleophile in the presence of protic acid. This strategy features good functional group tolerance, excellent yields and easy workup.

\section{ACKNOWLEDGEMENTS}

The authors are grateful to the Foundation of Hubei Educational Commission (No.B20111702) for financial support.

\section{REFERENCES}

1. E.M. Keramane, B. Boyer and J.P. Roque, Tetrahedron Lett., 42, 855 (2001).

2. D.A. Evans, D.H.B. Halstead and D.P. Campos, J. Am. Soc. Chem., 121, 6816 (1999).

3. A. Loupy, M. Pedoussaut and J. Sansoulet, J. Org. Chem., 51, 740 (1986).

4. G. Blay, M.L. Cardona, M.B. Garcia and J.R. Pedro, Synthesis, 438 (1989).

5. Y.Q. Wu, D.C. Limburg, D.E. Wilkinson, M.J. Vaal and G.S. Hamilton, Tetrahedron Lett., 41, 2847 (2000).

6. R. Kaul, Y. Brouillette, Z. Sajjadi, K.A. Hansford and W.D. Lubell, J. Org. Chem., 69, 6131 (2004).

7. P. Wasserscheid and W. Keim, Angew. Chem. Int. Ed., 39, 3772 (2000).

8. J.S. Wilkes, J. Mol. Catal. A, 214, 11 (2003).

9. V.I. Parvulescu and C. Hardacre, Chem. Rev., 107, 2615 (2007).

10. S. Zhou, L. Liu, B. Wang, F. Xu and R. Su, Asian J. Chem., 25, 240 (2013).

11. X. Sun, H. Luo and S. Dai, Chem. Rev., 112, 2100 (2012).

12. H. Sheikhloie, M.S. Tehrani and S.W. Husain, Asian J. Chem., 25, 1831 (2013).

13. D. Ingildeev, F. Hermanutz, K. Bredereck and F. Effenberger, Macromol. Mater. Eng., 297, 585 (2012).

14. Z. Jiao and X. Fang, Asian J. Chem., 25, 2143 (2013).

15. H. Ohno, "Electrochemical Aspects of Ionic Liquids", Wiley, New York (2005).

16. Q. Ren, S. Dong, J. Wu, F. Li and J. Miao, Asian J. Chem., 24, 5377 (2012).

17. M.D. Joshi and J.L. Anderson, RSC Adv., 2, 5470 (2012).

18. L. Wang, H. Zhu, C. Ma and Y. Yan, Asian J. Chem., 25, 2129 (2013).

19. S. Boovanahalli, D.W. Kim and D. Chi, J. Org. Chem., 69, 3340 (2004).

20. R. Sheldon, Chem. Commun., 2399 (2001).

21. N. Gupta, G.L. Kad and J. Singh, Catal. Commun., 8, 1323 (2007).

22. A.R. Hajipour, M. Mostafavi and A.E. Ruoho, Monatsh. Chem., 138, 569 (2007)

23. B.M. Wei, Z.Y. Zhang, Z.Q. Dai and K.C. Zhang, Monatsh. Chem., 142, 1029 (2011).

24. E. Janus, L. Goc-Maciejewska, M. Lozynski and J. Pernak, Tetrahedron Lett., 47, 4079 (2006).

25. H. Guo, J.L. Wang, X. Li, D.S. Lv and X.F. Lin, Chin. J. Catal., 32, 162 (2011).

26. B.J. Cox, S. Jia, Z.C. Zhang and J.G. Ekerdt, Polym. Degrad. Stab., 96, 426 (2011).

27. J. Buckingham, Dictionary of Organic Compounds, Routledge, New York (1982).

28. N.L. Lancaster, T. Weltib and G.B. Yong, J. Chem. Soc., Perkin Trans. II, 2267 (2001). 